\title{
Covid-19 Global Demographic Research Needs? Replacing Speculative Commentaries with Robust Cross-national Comparisons
}

Eva Beaujouan

Follow this and additional works at: https://knowledgecommons.popcouncil.org/series_pdr_essays-covid How does access to this work benefit you? Let us know!

\section{Recommended Citation}

Beaujouan, Eva. "Covid-19 Global Demographic Research Needs? Replacing Speculative Commentaries with Robust Cross-national Comparisons." In Covid-19 and the Global Demographic Research Agenda, edited by Landis MacKellar and Rachel Friedman, 8-14. New York: Population Council, 2021. 


\title{
Covid-19 Global Demographic Research Needs? Replacing Speculative Commentaries with Robust Cross-national Comparisons
}

\author{
EVA BEAUJOUAN
}

THE WORLD IS currently undergoing a pandemic-induced crisis transformative of human needs and behaviors. How can demographers contribute to understanding Covid-19 and its consequences? Disparities between countries, and social, gender, and economic inequalities within them, were present well before the crisis and long studied by demographers. Covid-19 presents demographic researchers with a renewed and enhanced opportunity to contribute to the fight against inequality. Demographers can assist countries in their recoveries over forthcoming years by collecting, compiling, and analyzing data on how the crisis unfolded, generating knowledge about changes in social and individual behaviors and adjustments in the population, and identifying what triggered them. Highlighting how the crisis and policy responses to it affected people may help policymakers better promote resilience and prepare for future crises-assuredly the next disease crisis, but also notably the climate emergency as well. In this comment, I argue that the Covid-19 crisis has increased the need for international comparisons, and hence for better comparative data.

\section{Why Do We Need International Comparisons?}

Cross-country studies are central to understanding demographic processes, and frameworks dear to demographers such as the demographic and epidemiological transitions, and Esping-Andersen's welfare state classification, could not have been developed without comparative data. Such studies allow unraveling the mechanisms that underpin macro-level trends and inter-

Eva Beaujouan, University of Vienna (Wittgenstein Centre for Demography and Global Human Capital [IIASA, OeAW, Univ. Vienna]). 
country disparities, but they are time- and data-intensive. Despite a surge in comparative Covid-19 mortality studies (Dudel et al. 2020; Esteve et al. 2020; Kontis et al. 2020), such comparisons are likely to be underrepresented in most explorations of the consequences of the pandemic, particularly in those that focus on the role of socioeconomic factors, as well as on processes that are difficult to quantify such as migration and union dynamics. The challenges are compounded by the fact that these processes require data on individual characteristics and contextual variables as well as measurement of the demographic outcomes.

The crisis affects society at different levels, and beyond the health aspect it has important economic and social effects that vary by country. The illness and Covid-associated "lockdowns" (one of the Oxford English Dictionary's Words of the Year for 2020, borrowed from American prison argot) have, directly or indirectly, led to an explosion in unemployment, precarity, and economic uncertainty, and a deepening of social, gender, or ethnic inequalities (Copley et al. 2020; Farré et al. 2020; Lambert et al. 2020; Magnusson et al. 2020; Reichelt et al. 2020). Depending on the prevalence of the virus in the country and on the response, a significant share of persons are suffering mental and physical health issues associated with Covid-19, the lockdowns, and uncertainty (Xiong et al. 2020).

If research is confined to the most-affected countries, the richest countries, or countries with the best data, this can lead to a biased perception of the impact of Covid-19. Aassve et al. (2020) expect very different consequences of the crisis for fertility depending on the world area, and particularly its socioeconomic development. The same way, migration and health longterm impact will probably vary depending on the country. Countries have not been evenly exposed to the pandemic, they differ in social organization and demographic structure, and have not reacted in the same way. Results derived from a single context would thus likely lead to a misunderstanding of the crisis and its consequences.

Cross-national comparative studies to understand the impact of differences in culture, preparedness, and policy responses are particularly difficult to implement because of the diversity of the units of analysis at least at three levels: economic and cultural diversity, demographic variation, and data comparability between countries. World areas are at different levels of development, and also within areas, variations occur, linked, for instance to the political and welfare regime. Countries' demographic characteristics vary according to their stage of the demographic transition, but even at similar stages, differences in culture, economy, and health system lead (among others) to different family structure and fertility levels, migration mechanisms, and life expectancy. And finally, there is a large inconsistency in data available across the world but also in very similar countries.

Despite, but also because of, these challenges, a set of robust, comparative observations across multiple countries is needed to allow countries to 
assess the success of their short- and long-term responses, relative to other countries, in achieving wanted results in the face of the crisis while avoiding unwanted ones. They can reveal structural regularities-whether of demographic, social, or governance dimension-with meaningful implications for policy (Kontis et al. 2020). This implies carefully taking the above-mentioned considerations into account. Notably, to tailor the studies to analyze a small sample of countries that are credible comparators, for instance regional comparative studies; to implement the analyses taking into account the demographic structure and welfare regime by isolating shared and country-specific features; but above all, to increase the capacity to collect and disseminate comparative data.

\section{Toward Comparative Studies on Fertility and Family in the High-Income Countries}

I pursue with examples how studies of fertility and family in the high-income countries would benefit from international comparisons and data. During the short- and medium-term crisis, suddenly altered circumstances probably lead to fertility postponement. This would result from the adverse economic situation, uncertainty about what the future holds, changes in partnership dynamics due notably to closure of social venues, decreased sexual activity (documented in several high-income countries), and more uneven access to health care and Assisted Reproductive Technologies (ART). On the other hand, more difficult access to abortion and to contraception in some settings, as well as an increase in intimate partner sexual coercion and assault may trigger a rise in unwanted births following the lockdowns. Preliminary findings on fertility intentions in the initial phase of the pandemic point to a birth recession in the high-income countries, but the extent of such a downturn in fertility is likely to vary across contexts (Lindberg et al. 2020; Luppi et al. 2020). In addition, as conditions ease, lagging economic recovery, delay in leaving the parental home, weakened intentions to have children, as well as having reached the biological age limit for fertility or no longer being able to pay for ART, can lead to an inability to recuperate lost fertility. Country conditions will probably determine to which extent the downward blip on fertility will be made up as societies return to a pre-pandemic norm. To observe these various aspects, local specialized studies will be very useful, but to generalize them, comparative studies are needed.

Research on the family consequences of Covid-19 has started, but it is scattered across different countries and suffers from a lack of data (Guetto et al. 2020; Relationships Australia 2020; Wagner et al. 2020; Wilde et al. 2020). As in the case of employment and mortality (Drefahl et al. 2020; ECDC 2020), the crisis may more strongly affect already-disadvantaged people, because they are more likely to experience economic hardship and this increases the 
likelihood of separation and the transition to a single-parent family. Younger generations, already at a particular disadvantage compared to their parents, may see their situation worsen: delayed family formation, fragilized romantic relationships, "boomerang" return to parents' residence, school- or university dropout. Family organization particularly suffered during the lockdowns, mostly due to the erosion of hard-won improvements in the gender division of labor in the home and women leaving the labor force to care for children. They will find it hard to get back in. Finally, reduced ART access and the lack of time to catch up on postponed births mentioned above may reinforce the inability of women with a high level of education to have all the children they originally wanted.

Overall, we can propose tentative theories and we have the know-how to study the consequences of the crisis for fertility and the family (and I think that we can generalize this to other aspects of demographic behavior). However, to understand what underlies changing family dynamics in the age of Covid-19, we need to set these studies in their international context, and for this we need data.

\section{Data Needs and Data Resources}

Beside drawing attention to wide cultural and structural variations between countries, for demographers the crisis has underlined the preexisting differences in data availability. Countries in which register data linked to other administrative datasets are available are best placed to conduct advanced studies of the impact of Covid-19 on the population. Other countries are critically short of data and have not been able to conduct surveys specific to the Covid-19 period, which will lead to a severe lack of information on the impact of the virus.

Data useful to study the consequences of the Covid-19 pandemic vary in nature. Repeat surveys, retrospective surveys, and population registers are useful to observe breaks in trends during the crisis and variations across countries, even without adding Covid-specific questions. Purpose-designed surveys with a few questions related to the pandemic (for instance change in economic situation, in fertility plans, in health), as well as panel studies following individual situations, can bring additional information about the shortterm consequences of the Covid-19 pandemic, and be asked across multiple countries. In addition, cross-country population surveys can be adapted by adding Covid-specific questions during or after the pandemic. Such surveys have the advantage of having an existing set of core questions that identify individual and household characteristics (e.g., social status, level of education, birth histories); alongside which, details about the pandemic can be explored. Finally, digital data also have a large potential to bring insights on the crisis. 
In light of this, the need to strengthen cross-national data infrastructure for integrating data from different types of sources, registers, as well as surveys is becoming more pressing. The Human Mortality Database helps monitor excess deaths across the high-income countries with its Short-term Mortality Fluctuations data series, and INED has developed a database on the Demography of Covid-19 Deaths by age and sex (https://dc-covid.site.ined.fr/en/) in response to the pandemic. Other consequences of Covid-19 across countries may be observed later via the Human Fertility Database, IPUMS-international that provides micro census data, and the IMAGE project that has assembled comparative statistics on internal migration (www.imageproject.com.au). But such data are not sufficient to compare social inequalities, for which detailed individual data with a uniform survey design across countries are necessary. Population surveys that belong to the Generation and Gender Programme and SHARE offer core demographic questions common to a range of highincome countries, and together with studies with smaller samples such as the World Value Surveys or European Social Survey they will be very valuable, especially if they ask pandemic-related questions. Register data linked to administrative data could be made available for use in more countries, but this requires working further on the legal and institutional framework of making such data available for research (FORS and inkhub.ch 2020). Availability and distribution of international data have advanced in the last two decades, but we still lack a central repository, or even a definitive source of advice on the availability of comparative data that would provide a foundation for international projects and facilitate the development of international research.

\section{Conclusion: Further Develop Robust, Cross- Nationally Comparative Datasets}

The overarching research agenda of demographic research may not change much: trying to improve the living conditions of people across the planet by helping societies "understand and anticipate the population dynamics they are experiencing" (UNFPA 2020, p. 2). With this crisis, we have stronger reasons and incentives to carry it through. Demographers have been working for a long time with epidemiologists, geographers, economists, sociologists, reproductive health specialists, and so forth. Uniting further with other disciplines that bring their skills, perspectives, and data would help to answer the needs emerging from the crisis, and facilitate clear and timely communication of results. For demographers to most effectively bring their insights to bear on Covid-19, however, we need to intensify our efforts to develop robust, crossnationally comparative datasets that extend beyond our traditional focus on simple summary indicators of births and deaths. 


\section{References}

Aassve, A., N. Cavalli, L. Mencarini, S. Plach, and M.L. Bacci. 2020. "The COVID-19 pandemic and human fertility," Science 369(6502): 370-371. https://doi.org/10.1126/science. abc9520.

Copley, A., A. Decker, F. Delavelle, M. Goldstein, M. O’Sullivan, S. Papineni. 2020. “COVID-19 pandemic through a gender lens." Africa Knowledge in Time Policy Brief 1(2). Washington, DC: World Bank.

Drefahl, S., M. Wallace, E. Mussino, S. Aradhya, M. Kolk, M. Brandén, et al. 2020. “A population-based cohort study of socio-demographic risk factors for COVID-19 deaths in Sweden," Nature Communications 1-7. https://doi.org/10.1038/s41467-020-18926-3.

Dudel, C., T. Riffe, E. Acosta, A. Van Raalte, C. Strozza, and M. Myrskylä. 2020. “Monitoring trends and differences in COVID-19 case-fatality rates using decomposition methods: Contributions of age structure and age-specific fatality," PLOS ONE 15(9) e0238904. https://doi.org/10.1371/journal.pone.0238904.

Esteve, A., I. Permanyer, D. Boertien, and J.W. Vaupel. 2020. “National age and coresidence patterns shape COVID-19 vulnerability," PNAS 117(28): 16118-16120. https://doi. org/10.1073/pnas.2008764117.

European Centre for Disease Prevention and Control (ECDC). 2020. "COVID-19 clusters and outbreaks in occupational settings in the EU/EEA and the UK." Stockholm: ECDC.

Farré, L., Y. Fawaz, L. González, and J. Graves. 2020. "How the COVID-19 lockdown affected gender inequality in paid and unpaid work in Spain." IZA Institute of Labor Economics. IZA Discussion Paper Number 13434. https://ssrn.com/abstract=3643198.

FORS and linkhub.ch. 2020. "Accessing and linking data for research in Switzerland." Report. https://linkhub.ch/wp-content/uploads/2020/11/Report_Data_Access_and_Linking_11_2020-1.pdf.

Guetto, R., D. Vignoli, and G. Bazzani. 2020. "Marriage and cohabitation under uncertainty: The role of narratives of the future during the COVID-19 pandemic," European Societies. https://doi.org/10.1080/14616696.2020.1833359.

Kontis, V., J.E. Bennett, T. Rashid, R.M. Parks, J. Pearson-Stuttard, M. Guillot, et al. 2020. "Magnitude, demographics and dynamics of the effect of the first wave of the COVID-19 pandemic on all-cause mortality in 21 industrialized countries," Nature Medicine. https:// doi.org/10.1038/s41591-020-1112-0

Lambert, A., J. Cayouette-Remblière, É. Guéraut, G. LeRoux, C. Bonvalet, V. Girard, and L. Langlois. 2020. "How the COVID-19 epidemic changed working conditions in France," Population and Societies No. 579.

Lindberg, L.D., A. Vandevusse, J. Mueller, and M. Kirstein. 2020. “Early impacts of the COVID-19 Pandemic: Findings from the 2020 Guttmacher Survey of Reproductive Health Experiences." Guttmacher Institute report. https://www.guttmacher.org/report/earlyimpacts-covid-19-pandemic-findings-2020-guttmacher-survey-reproductive-health

Luppi, F., B. Arpino, and A. Rosina. 2020. "The impact of COVID-19 on fertility plans in Italy, Germany, France, Spain, and the United Kingdom," Demographic Research 43(47): 1399-1412. https://doi.org/10.4054/DemRes.2020.43.47.

Magnusson, K., K. Nygård, L. Vold, and K. Telle. 2020. “Occupational risk of COVID-19 in the lst vs 2nd wave of infection," medRxiv preprint.

Reichelt, M., K. Makovi, and A. Sargsyan. 2020. "The impact of COVID-19 on gender inequality in the labor market and gender-role attitudes," European Societies.

Relationships Australia. 2020. "COVID-19 and its effects on relationships." Survey report. https://www.relationships.org.au/what-we-do/research/online-survey/MaySurveyResults.pdf 
UNFPA. 2020. “Demographic resilience programme for Europe \& Central Asia." https://eeca. unfpa.org/en/publications/demographic-resilience-programme-europe-central-asia.

Wagner, B.G., K.H. Choi, and P.N. Cohen. 2020. "Decline in marriage associated with the COVID-19 pandemic in the United States." SocArXiv preprint. https://doi.org/10.31235/ osf.io/x6ph4.

Wilde, J., W. Chen, and S. Lohmann. 2020. “COVID-19 and the future of US fertility: What can we learn from Google? IZA discussion paper no. 13776.

Xiong, J., O. Lipsitz, F. Nasri, L.M.W. Lui, H. Gill, L. Phan, et al. 2020. “Impact of COVID-19 pandemic on mental health in the general population: A systematic review," Journal of Affective Disorders 277: 55-64. https://doi.org/10.1016/j.jad.2020.08.001. 